\title{
Article \\ Rehabilitation Process Issues and Functional Performance after Total Hip and Knee Replacement
}

\author{
Alexander S. Fedonnikov ${ }^{1}$, Elena A. Andriyanova ${ }^{1}$, Anton R. Kiselev ${ }^{1,2, *(D)}$ and Igor A. Norkin ${ }^{1}$ \\ 1 Institute of Public Health, Health Management and Humanitarian Problems of Medicine, \\ Research Institute of Traumatology, Orthopedics and Neurosurgery, Saratov State Medical University, \\ 410012 Saratov, Russia; fedonnikov@mail.ru (A.S.F.); andriyanova@yandex.ru (E.A.A.); \\ norkin@sarniito.com (I.A.N.) \\ 2 National Medical Research Center for Therapy and Preventive Medicine, 101990 Moscow, Russia \\ * Correspondence: antonkis@list.ru; Tel.: +7-499-5536938
}

Citation: Fedonnikov, A.S.; Andriyanova, E.A.; Kiselev, A.R.; Norkin, I.A. Rehabilitation Process Issues and Functional Performance after Total Hip and Knee Replacement. Healthcare 2021, 9, 1126 https://doi.org/10.3390/ healthcare 9091126

Academic Editor: Rahman Shiri

Received: 7 April 2021

Accepted: 24 August 2021

Published: 30 August 2021

Publisher's Note: MDPI stays neutral with regard to jurisdictional claims in published maps and institutional affiliations.

Copyright: (c) 2021 by the authors. Licensee MDPI, Basel, Switzerland. This article is an open access article distributed under the terms and conditions of the Creative Commons Attribution (CC BY) license (https:// creativecommons.org/licenses/by/ $4.0 /)$.

\begin{abstract}
Background: to ensure satisfactory outcomes in patients who have undergone total hip or knee replacement, it is crucial to prioritize postoperative rehabilitation process and its management rather than the successful surgery alone. The goal of our study was to investigate the outcomes of rehabilitation process after the total hip or knee replacement, including local orthopedic follow-up, communication with local health authorities, patients' satisfaction regarding rehabilitation, and their functional performance after the surgery. (2) Methods: the study included 523 patients who underwent total hip replacement, and 650 patients who underwent total knee replacement. All patients were surveyed via formalized phone interviews containing questions related to postoperative rehabilitation parameters and outcomes. (3) Results: in postsurgical period, nearly $70 \%$ of patients had regular local orthopedic follow-up. Lack of the latter at the local level was indicated by approximately $10 \%$ of patients, and the rest of the respondents note the practice of sporadic follow-up. Half of patients reported pains of various severity. Good physical activity (e.g., ability to walk unassisted within their residential district) was acknowledged by about a quarter of patients. Ability to walk unassisted was reported by just $54.5 \%$ of patients. (4) Conclusions: the disproportion between generally high patient satisfaction of rehabilitation management $(>80 \%)$ and low feedback level on the part of local health authorities $(9.4 \%)$ demonstrated lack of communication between the key parties involved in the rehabilitation process.
\end{abstract}

Keywords: total hip replacement; total knee replacement; rehabilitation management; social survey

\section{Introduction}

Osteoarthritis of knee and hip joints is among the most significant disorders of the musculoskeletal system and connective tissue. It has high prevalence rate due to progressive population aging, diminishing physical activity, along with growing obesity and injury rates [1,2]. Considerable impact of knee and hip osteoarthritis on work capability and quality of life represents the social aspect of this problem [3]. Principal surgical approach to treating severe hip and knee osteoarthritis is total joint replacement [4-6]. For example, the prevalence rates of total hip replacement (THR) and total knee replacement (TKR) in the USA population in 2010 were $0.83 \%$ and $1.52 \%$, respectively [7]. Population analysis of patients who underwent THR or TKR is habitually performed using specialized registries [8-10]. In Russia, there is no unique national registry for such patients, and, consequently, there are no apparent epidemiological data [11]. Moreover, in the last decade, persistent growth of THR and TKR surgeries was observed in Russia [12]. To ensure satisfactory outcomes in patients who underwent THR or TKR, it is vital to prioritize their postoperative rehabilitation process and its management rather than the successful surgery alone [13]. Sufficiently large cohorts of concerned postoperative patients are formed, which requires to investigate possible differences in rehabilitation evaluation by THR vs. TKR 
patients in order to provide the most effective individual approach to their rehabilitation process. The situation is complicated by the personnel shortage in outpatient facilities for orthopedic services. It is worth noting that the shortage rate, according to the Ministry of Healthcare of Russia is about $40 \%[14,15]$.

Hence, the described situation determines the goal of this study which was to investigate the outcomes of rehabilitation process after the total hip or knee replacement, including local orthopedic follow-up, communication with local health authorities, patients satisfaction regarding rehabilitation, and their functional performance after the surgery.

\section{Materials and Methods}

\subsection{Study Design}

Our study involved 1173 patients who met the following enrollment criteria:

(i) They underwent THR or TKR surgery between 1 January 2015 and 30 June 2016, at Research Institute of Traumatology, Orthopedics and Neurosurgery of Saratov State Medical University;

(ii) They were diagnosed with unilateral coxarthrosis (M16) or gonarthrosis (M17);

(iii) They were over 18 years of age.

The exclusion criteria for prospective study participants were as follows:

(i) Their contact information in medical records was absent or outdated;

(ii) They could not be reached by phone calls;

(iii) They did not respond to all questions of the survey.

From the local database of medical records, we obtained the following data for each patient included in our study: age, gender, place of residence, ICD-10 code of their diagnosis, and surgery type. Bilateral osteoarthritis was excluded in order to investigate the rehabilitation process in patients who first encountered the osteoarthritis problem.

All patients were surveyed in order to collect data regarding their rehabilitation and its outcomes.

\subsection{Participants}

Patients included in the study were distributed among two groups. The first group was composed of subjects ( $n=523 ; 65.2 \%$ females) who underwent THR. The second group comprised the patients ( $n=650 ; 88.2 \%$ females) who underwent TKR. Such patient assignment to the study groups was performed in order to explore possible differences in rehabilitation evaluation by THR vs. TKR patients.

Subjects participating in our study reside permanently in 24 regions of 5 federal districts in Russia. Respondents from Southern (39.3\%) and North Caucasian districts $(31.7 \%)$ prevailed.

This study was approved by the Ethics Committee (Minutes No. 1 of 5 September 2016) at Saratov State Medical University (Saratov, Russia). The written informed consent was obtained from all participants.

\subsection{Questionnaire Survey}

All patients were surveyed via formalized phone interviews. Each survey session lasted approximately $15 \pm 2 \mathrm{~min}(\mathrm{M} \pm \mathrm{SD}$ ) and was recorded. Prior to the survey, the interviewers were thoroughly instructed about the study goal, the structure of the questionnaire, and the manner of conversing with respondents. The full text of the questionnaire is presented in Appendix A. The questionnaire was developed at Research Institute of Traumatology, Orthopedics and Neurosurgery of Saratov State Medical University. It includes the questions about the most important issues of rehabilitation process and its functional outcomes.

Our survey contained the questions related to evaluation of postsurgical rehabilitation process parameters (regularity of a local orthopedic monitoring, communication with local health authorities, evaluation of local rehabilitation management), and re- 
habilitation outcomes (evaluation of chronic pain, physical activity, limb function and anatomical changes).

For self-rated evaluation of the chronic pain severity by the patients, we used the principle of verbal descriptor scale (VDS). To fill in Section 2.1 of the questionnaire, the following VDS categories were used to explain the patients how to describe the pain severity: No pain (self-explanatory), Mild (i.e., annoying pain), Nagging (i.e., uncomfortable pain), Distressing (i.e., miserable pain), Intense (i.e., horrible pain), Worst possible (i.e., unbearable pain).

Only entirely (100\%) filled questionnaires were included in further statistical analysis.

\subsection{Statistical Analysis}

We used the Shapiro-Wilk test to examine whether the distribution of a variable is normal. We reported median, and lower and upper quartiles for the variables that were not normally distributed and mean and standard deviation for the normally distributed variables. Binary variables were presented as proportions (in percentages) with $95 \%$ confidence intervals. We applied the Chi-squared $\left(\chi^{2}\right)$ test to compare the proportions among the groups.

\section{Results}

The study encompassed 1173 patients ( $77.9 \%$ females) with an average age of $61(55,68)$ years, who underwent THR or TKR. After distributing the patients among two study groups, THR patients $(n=523)$ were, on average, $54(39,70)$ years of age, whereas TKR patients $(n=650)$ were, on average, $59(45,72)$ years old. Age distribution in groups of patients is presented in Figure 1. The latter reveals the following age trends vs. surgery type: THR prevailed in subjects $18-52$ years old, while those $53-82$ years old had primarily TKR.

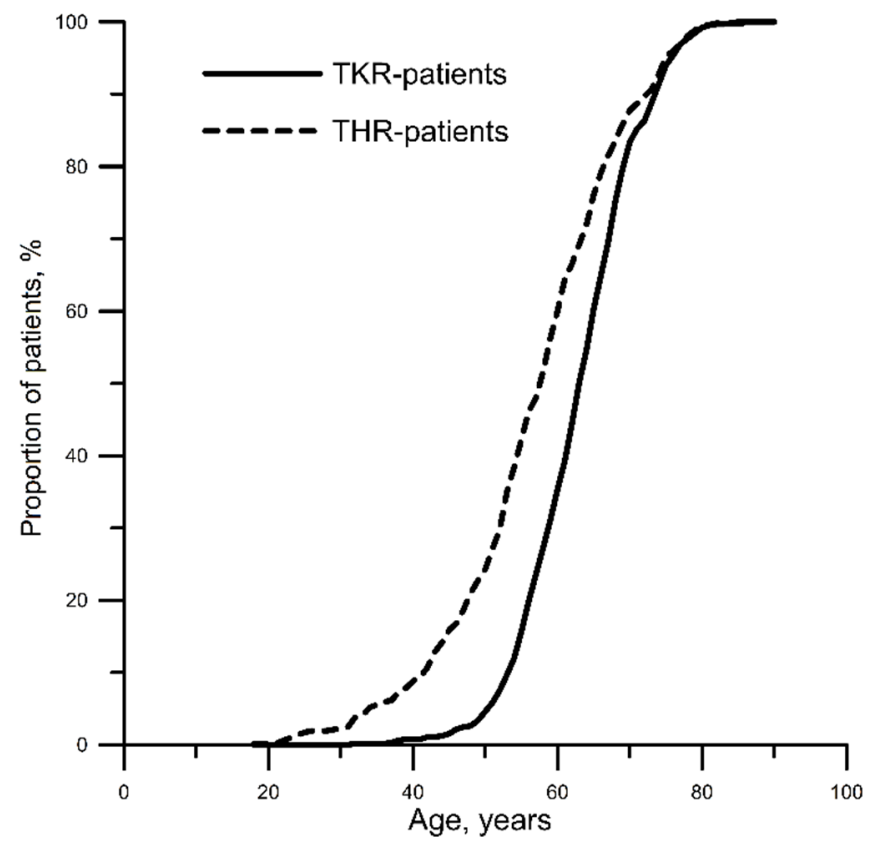

Figure 1. Patient age distribution versus surgery type. THR, total hip replacement; TKR, total knee replacement.

Average (mean \pm standard deviation) length of stay at inpatient facility was $8.8 \pm 0.3$ days.

As for time that has elapsed after the surgery, absolute majority of subjects passed the early postsurgical period (95.8\% of THR-patients and $94.4 \%$ of TKR-patients) (Table 1). Thus, the distribution of patients allows the regularity of outpatient visits to healthcare pro- 
fessionals to be correctly estimated. Bearing in mind the absence of statistically significant differences in postsurgical time for THR vs. TKR patients, and the striking predominance of patients with postoperative period of 6 months or more, further data analysis regarding rehabilitation and outcomes was carried out without considering the postsurgical time frame all.

Table 1. Distribution of patients who underwent THR or TKR according to postsurgical time frame.

\begin{tabular}{cccc}
\hline Time Elapsed after the Surgery, Months & THR-Patients $(\boldsymbol{n = 5 2 3 )}$ & TKR-Patients $(\boldsymbol{n = 6 5 0 )}$ & $\boldsymbol{p}$-Value \\
\hline Under 3 & $4.2(2.7-6.3)$ & $5.6(4.0-7.7)$ & 0.27 \\
3-6 & $8.0(5.8-10.7)$ & $8.9(6.8-11.4)$ & 0.58 \\
$6-12$ & $25.1(21.4-29.1)$ & $28.0(24.6-31.6)$ & 0.27 \\
Over 12 & $62.7(58.4-66.9)$ & $57.5(53.6-61.3)$ & 0.07 \\
\hline
\end{tabular}

Data are presented as proportions (in percentages) with $95 \%$ confidence interval. THR, total hip replacement; TKR, total knee replacement.

In postsurgical period, about $70 \%$ of patients had regular local orthopedic followup, while $10 \%$ had none at all. We established statistically significant difference of orthopedic follow-up between patients who underwent THR vs. those who underwent TKR: 1.5 more patients who underwent TKR do not have local orthopedic postsurgical monitoring. About $70 \%$ of patients in both groups confirmed that they visited a local orthopedic surgeon voluntarily. However, for THR patients, it was more distinctive $(74.2 \%$ against $68.7 \%)$ at a statistically significant level (Table 2$)$.

Table 2. Rehabilitation process after the THR or TKR surgery.

\begin{tabular}{|c|c|c|c|c|}
\hline No. & Survey Results & $\begin{array}{l}\text { THR Patients } \\
\quad(n=523)\end{array}$ & $\begin{array}{l}\text { TKR Patients } \\
\quad(n=650)\end{array}$ & $p$-Value \\
\hline \multicolumn{5}{|c|}{ Local orthopedic postsurgical monitoring } \\
\hline 1.1.1. & $\begin{array}{c}\text { Regular (after 3, 6, } 12 \text { months; annually } \\
\text { afterwards *) visits to a local orthopedic } \\
\text { surgeon }\end{array}$ & $73.2(69.2-77.0)$ & $66.5(62.7-70.1)$ & 0.01 \\
\hline 1.1.2. & Irregular visits to a local orthopedic surgeon & $17.4(14.3-20.9)$ & $19.4(16.4-22.7)$ & 0.38 \\
\hline 1.1.3. & No local orthopedic monitoring & $9.2(6.9-12.0)$ & $13.6(11.1-16.5)$ & 0.02 \\
\hline 1.1.4. & Other & $0.2(0.01-1.1)$ & $0.5(0.1-1.4)$ & 0.40 \\
\hline \multicolumn{5}{|c|}{ Communication with local health authorities } \\
\hline 1.2.1. & $\begin{array}{l}\text { Feedback from regional health services } \\
\text { representative offering a rehabilitation course }\end{array}$ & $8.6(6.3-11.3)$ & $8.8(6.7-11.3)$ & 0.90 \\
\hline 1.2.2. & Voluntary visits to a local orthopedic surgeon & $74.2(70.2-77.9)$ & $68.7(65.0-72.3)$ & 0.04 \\
\hline 1.2.3. & $\begin{array}{l}\text { Voluntary consultation with the orthopedic } \\
\text { surgeon who performed the surgery } \\
\text { Absence of both communication with }\end{array}$ & $7.6(5.5-10.2)$ & $10.6(8.3-13.2)$ & 0.08 \\
\hline 1.2.4. & $\begin{array}{c}\text { healthcare system representative and actual } \\
\text { rehabilitation }\end{array}$ & $9.4(7.0-12.2)$ & $11.7(9.3-14.4)$ & 0.21 \\
\hline 1.2.5. & Other & $0.2(0.01-1.1)$ & $0.2(0.01-0.9)$ & 1.00 \\
\hline \multicolumn{5}{|c|}{ Evaluation of postsurgical rehabilitation process at the place of residence } \\
\hline 1.3.1. & Entirely satisfied & $71.5(67.4-75.3)$ & $71.8(68.2-75.2)$ & 0.91 \\
\hline 1.3.2. & $\begin{array}{c}\text { Overall, the evaluation of rehabilitation } \\
\text { process is positive; however, it needs } \\
\text { improvement }\end{array}$ & $8.2(6.0-10.9)$ & $8.6(6.6-11.0)$ & 0.81 \\
\hline 1.3.3. & Absolutely dissatisfied & $19.1(15.8-22.7)$ & $18.6(15.7-21.8)$ & 0.83 \\
\hline 1.3.4. & Evaluation is impossible (choosing 1.2.4) & $1.1(0.4-2.4)$ & $0.9(0.3-2.0)$ & 0.73 \\
\hline
\end{tabular}

Data are presented as proportions (\%) with $95 \%$ confidence intervals. THR, total hip replacement; TKR, total knee replacement.

Overall, no more than $9 \%$ of patients in both groups indicated active rehabilitation support on the part of local health authorities; about $10 \%$ of subjects in both groups specified actual absence of rehabilitation at the local level. Voluntary consultation with the orthopedic surgeon who has performed the surgery was admitted by $7.6-10.6 \%$ of patients in both groups (Table 2). 
Evaluation results demonstrated that about $70 \%$ of patients were fully satisfied with the local management of their postsurgical rehabilitation. Approximately $20 \%$ of surveyed subjects were unequivocally dissatisfied. Major causes for dissatisfaction were associated with a poor healthcare quality (no result after visiting a local orthopedic surgeon) and absence of a local orthopedic surgeon. No statistically significant differences between the groups were revealed (Table 3).

Table 3. Causes of rehabilitation process dissatisfaction.

\begin{tabular}{ccccc}
\hline No. & Survey Results & $\begin{array}{c}\text { THR Patients } \\
(\boldsymbol{n}=\mathbf{7 8})\end{array}$ & $\begin{array}{c}\text { TKR Patients } \\
(\boldsymbol{n}=\mathbf{9 9 )})\end{array}$ & $\boldsymbol{p}$-Value \\
\hline 1.3.3.1. & Absence of a local orthopedic surgeon & $21.8(13.2-32.6)$ & $30.3(21.5-40.4)$ & 0.21 \\
1.3.3.2. & Lack of time for visiting a local orthopedic surgeon & $10.3(4.6-19.3)$ & $10.1(5.0-17.8)$ & 0.97 \\
1.3.3.3. & Poor healthcare quality (no result after visiting a local & $26.9(17.5-38.1)$ & $30.3(21.5-40.4)$ & 0.62 \\
1.3.3.4. & orthopedic surgeon) & $41.0(30.0-52.7)$ & $29.3(20.6-39.3)$ & 0.11 \\
\hline
\end{tabular}

Data are presented as proportions (\%) with $95 \%$ confidence intervals. THR, total hip replacement; TKR, total knee replacement. Note that the total number of patients does not match the same number in question 1.3.3 (see Table 2), because not all respondents indicated the reasons of rehabilitation management dissatisfaction.

The analysis of chronic pain in patients showed that nearly half of them experienced pain of some degree of severity. Absence of pain was more often stated by THR patients; whereas nagging, uncomfortable pain was more frequently admitted by TKR patients at a statistically significant level (Table 4).

Table 4. Rehabilitation outcomes/Functional performance.

\begin{tabular}{|c|c|c|c|c|}
\hline No. & Survey Results & $\begin{array}{l}\text { THR Patients } \\
\quad(n=523)\end{array}$ & $\begin{array}{l}\text { TKR Patients } \\
\quad(n=650)\end{array}$ & $p$-Value \\
\hline \multicolumn{5}{|c|}{ Chronic pain evaluation } \\
\hline 2.1.1.1. & No pain & $56.4(52.0-60.7)$ & $47.0(43.1-50.9)$ & $<0.01$ \\
\hline 2.1.1.2. & Mild, annoying pain & $25.1(21.4-29.1)$ & $26.2(22.9-29.8)$ & 0.67 \\
\hline 2.1.1.3. & Nagging, uncomfortable pain & $14.2(11.3-17.5)$ & $20.7(17.7-24.0)$ & $<0.01$ \\
\hline 2.1.1.4. & Distressing, miserable pain & $3.1(1.8-5.0)$ & $4.0(2.6-5.8)$ & 0.41 \\
\hline 2.1.1.5. & Intense, horrible pain & $0.8(0.2-2.0)$ & $1.5(0.7-2.8)$ & 0.27 \\
\hline 2.1.1.6. & Worst possible, unbearable pain & $0.4(0.1-1.4)$ & $0.6(0.2-1.6)$ & 0.63 \\
\hline \multicolumn{5}{|c|}{ Evaluation of physical activity, limb function and anatomic changes } \\
\hline \multicolumn{5}{|c|}{ Ability to walk } \\
\hline 2.2.1.1. & Unable to walk & $2.1(1.1-3.7)$ & $3.8(2.5-5.6)$ & 0.09 \\
\hline 2.2.1.2. & $\begin{array}{c}\text { Able to walk with extra support (cane, } \\
\text { crutches) }\end{array}$ & $40.5(36.3-44.9)$ & $44.0(40.1-47.9)$ & 0.23 \\
\hline 2.2.1.3. & Able to walk independently & $57.4(53.0-61.7)$ & $52.2(48.3-56.1)$ & 0.08 \\
\hline \multicolumn{5}{|c|}{ Range of walking without rest } \\
\hline 2.2.2.1. & Able to move inside the house & $14.5(11.6-17.8)$ & $19.8(16.8-23.1)$ & 0.02 \\
\hline 2.2.2.2. & Able to reach nearby facilities & $29.6(25.7-33.7)$ & $31.5(27.9-35.2)$ & 0.48 \\
\hline 2.2.2.3. & Able to walk several blocks & $31.2(27.3-35.4)$ & $27.5(24.1-31.1)$ & 0.17 \\
\hline 2.2.2.4. & $\begin{array}{l}\text { Able to walk unassisted within the } \\
\text { residential district }\end{array}$ & $24.7(21.1-28.6)$ & $21.2(18.1-24.6)$ & 0.16 \\
\hline \multicolumn{5}{|c|}{ Anatomical and functional changes of the limb } \\
\hline 2.2.3.1. & Joint excursion (motion range) is restricted & $26.0(22.3-30.0)$ & $31.1(27.6-34.8)$ & 0.06 \\
\hline 2.3.1.1. & No difference in limb lengths & $72.9(68.9-76.7)$ & $78.2(74.8-81.3)$ & 0.04 \\
\hline 2.3.2.1. & No limb deformations & $93.9(91.5-95.8)$ & $91.7(89.3-93.7)$ & 0.15 \\
\hline
\end{tabular}

Data are presented as proportions (\%) with $95 \%$ confidence intervals. THR, total hip replacement; TKR, total knee replacement.

Capability to walk independently was stated by slightly over a half of patients. About $43 \%$ of patients were able to walk only with an extra support. Fewer than $25 \%$ of patients could walk unassisted within their residential district. We established that there were more 
people capable of moving solely around the house among TKR patients vs. THR patients at a statistically significant level (Table 4).

In fact, three quarters of patients had no difference in limb lengths. TKR patients kept the limb length more often than the subjects of another group, and the difference was statistically significant. Over $90 \%$ of patients stated no limb deformations. These findings imply that the surgical stage of treatment was performed correctly. However, nearly $30 \%$ of patients had joint excursion (motion range) restrictions (Table 4).

\section{Discussion}

In recent years, we have observed the intensive ongoing development of government programs on hip and knee replacement in Russia [16]. However, the availability of postsurgical rehabilitation to patients is limited due to insufficient resources [17], which could be the cause of the chronic pain persistence and low physical activity of patients. According to other medical and sociological studies, low rehabilitation effectiveness after the hip and knee replacement surgeries is associated with the fact that functional performance evaluation is virtually lacking, as well as with insufficient participation in supporting patients and an incomplete rehabilitation cycle at the outpatient follow-up treatment level in $26 \%$ of patients [18].

Our results confirmed our assumption that studying patient opinion about the rehabilitation outcomes regardless of their evaluation of some key points of their physical performance (chronic pain, orthopedic parameters and physical activity) does not benefit the correct analysis of rehabilitation management effectiveness. According to our data, over $80 \%$ of patients expressed their satisfaction with rehabilitation quality, albeit the presence of permanent pain was attributed to nearly $45 \%$ of surveyed subjects.

The above assumption and obtained results were confirmed in different studies of joint replacement outcomes and rehabilitation strategies. According to some published research projects conducted in other countries, the main complaints of patients in postsurgical period were related to their lameness and pain. These issues may bother patients for several years after the surgery, even in case of implant stability confirmed by X-ray examination [19]. An importance of monitoring the chronic pain as a major factor, influencing quality of life after the surgery, was described in other publications [20,21].

Subjective evaluation of a patient's physical activity should be also taken into consideration in terms of the walking distance and the motion range of both operated and unoperated hip joints [22].

Difference in leg lengths is often considered a problem after the THR surgery, and may adversely affect an otherwise favorable outcome. Furthermore, it has been associated with a patient dissatisfaction, and remains one of the most common reasons for litigation against the orthopedic community [23].

The clinical implication of the obtained results is associated with establishing the continuous feedback programs between patients and doctors (orthopedists, rehabilitation therapists, etc.) at the level of medical institutions, which would effectively monitor and control long-term medical and social results of complicated surgeries such as THR/TKR.

In order to improve this routine in the future, it is necessary to develop and introduce the feedback social services using digital technology of interactive online communication (web-platforms supported by medical institutions serving THR/TKR providers), which could be an effective organizational tool for controlling the long-term medical and social consequences of THR/TKR surgeries [24,25].

Over last few years, several studies dealing with chronic pain, patient mobility, necessity and advantages of a long-term rehabilitation for THR and TKR patients, including social surveys, were published [26,27]. We can also find very good examples of effective management strategies [28,29]. Hence, the results of the present study correspond to A. Donabedian's quality assurance methodology with respect to the outcomes [30] and may be potentially useful for researchers, health managers and physicians in the development of patient feedback technologies. 


\section{Limitations}

Chronic pain is among the major issues after the joint replacement: e.g., as many as $5-10 \%$ of TKR patients experience residual pains [31]. The complexity of the chronic pain assessment should be particularly emphasized: different approaches to pain intensity description have been published [32]; verbal descriptor scale, along with a numeric rating scale for pain intensity, could be used in medical practice, depending on the preference of a researcher and a respondent [33]. Pain evaluation simplicity in our study allowed obtaining relevant results, while more specific methods should be used for pain assessment with a higher reliability and validity $[34,35]$. The simplest scale used in our study could cause, without any doubt, some limitations, but still, it has yielded the results meeting the declared goal and methods.

The study participants were recruited from the single center (Research Institute of Traumatology, Orthopedics and Neurosurgery of Saratov State Medical University). They represented approximately $5 \%$ of THR/TKR annually performed in Russia $[16,17]$.

The study was conducted in actual clinical practice environment: hence, according to ethical reasons, it involved no patients without rehabilitation.

Among the limitations of our study, we should mention that we did not analyze the dependence of survey results on postsurgical period duration among THR vs. TKR patients.

We analyzed solely general and essential characteristics of THR and TKR patients regardless of the follow-up period duration.

For our data, we consider inappropriate to perform a more detailed analysis, taking into account that most patients were interviewed within 6 months or more after the surgery and that overall distributions of postsurgical time frames in THR vs. TKR patients were statistically comparable (Table 1).

\section{Conclusions}

The study revealed that approximately a quarter of patients who underwent total hip or knee replacement, had no regular local postoperative orthopedic follow-up. The significant disproportion between the high rate of declared generally positive attitude towards the rehabilitation management (over $80 \%$ of patients) and low feedback level on the part of local health authorities (9.4\%) has demonstrated lack of communication among the key parties in the rehabilitation process. Considering that more than $71 \%$ of patients affirmed entire satisfaction with rehabilitation process at the place of their residence, whereas just $54.5 \%$ of patients had a capability to walk unassisted, it could be concluded that this finding represented an actual medical and social problem requiring further studying.

Author Contributions: Conceptualization, A.S.F. and I.A.N.; methodology, A.S.F. and E.A.A.; validation, A.S.F., E.A.A. and A.R.K.; formal analysis, A.S.F. and A.R.K.; investigation, A.S.F. and E.A.A.; resources, I.A.N.; data management, A.S.F. and I.A.N.; writing-original draft preparation, A.S.F. and A.R.K.; writing-review and editing, A.S.F. and A.R.K.; visualization, A.S.F.; supervision, I.A.N.; project administration, A.S.F.; funding acquisition, A.S.F. and I.A.N. All authors have read and agreed to the published version of the manuscript.

Funding: This research received no external funding.

Institutional Review Board Statement: The study was conducted in accordance with the guidelines of the Declaration of Helsinki, and was approved by the Institutional Review Board (or Ethics Committee) of Saratov State Medical University (protocol 1 of 6 September 2016).

Informed Consent Statement: Informed consent was obtained from all subjects involved in the study.

Data Availability Statement: Not applicable.

Conflicts of Interest: The authors declare no conflict of interest. 


\section{Appendix A}

SURVEY

"Monitoring of Rehabilitation Process after Total Hip and Knee Replacement"

After self-introduction, an interviewer informs a surveyed person about the goal of the study and kindly asks them to accurately answer the following questions. While working with the questionnaire, an interviewer should circle the selected items or write down the answers.

1. Rehabilitation process after THR/TKR surgery.

1.1. Please, describe your local orthopedic follow-up after the surgery?

1.1.1. Regular (after 3, 6, 12 months; annually afterwards *) visits to a local orthopedic surgeon

1.1.2. Irregular visits to a local orthopedic surgeon

1.1.3. No local orthopedic follow-up

1.1.4. Other (indicate)

1.2. How your postoperative communication with local health authorities was organized?

1.2.1. Feedback from regional health services representative offering a rehabilitation course

1.2.2. Voluntary visits to a local orthopedic surgeon

1.2.3. Voluntary consultation with the orthopedic surgeon who has performed the surgery

1.2.4. Absence of communication with a healthcare system professional and actual rehabilitation

1.2.5. Other (indicate)

1.3. Please, evaluate postsurgical rehabilitation process at your place of residence.

1.3.1. Entirely satisfied

1.3.2. Overall, the evaluation of rehabilitation process is positive; however, it needs improvement

1.3.3. Absolutely dissatisfied.

Please, indicate causes of rehabilitation process dissatisfaction (relating to question 1.3.3):

1.3.3.1. Absence of a local orthopedic surgeon

1.3.3.2. Lack of time for visiting a local orthopedic surgeon

1.3.3.3. Poor healthcare quality (no result after visiting a local orthopedic surgeon)

1.3.3.4. Other (indicate)

1.3.4. Evaluation is impossible (choosing 1.2.4)

2. Rehabilitation outcomes/Functional performance

2.1. Chronic pain evaluation.

2.1.1. Please, describe pain severity according to the simple descriptive scale:

2.1.1.1. No pain

2.1.1.2. Mild, annoying pain

2.1.1.3. Nagging, uncomfortable pain

2.1.1.4. Distressing, miserable pain

2.1.1.5. Intense, horrible pain

2.1.1.6. Worst possible, unbearable pain

2.2. Physical activity, limb function

2.2.1. How can you describe your ability to walk?

2.2.1.1. Unable to walk

2.2.1.2. Able to walk with an extra support (cane, crutches)

2.2.1.3. Able to walk unassisted

2.2.2. What is your range of walking without rest?

2.2.2.1. Able to move around the house

2.2.2.2. Able to reach nearby facilities

2.2.2.3. Able to walk several blocks

2.2.2.4. Walks unassisted within the residential district

2.2.3. Please, evaluate your joint excursion (motion range) 


\subsubsection{Restricted}

2.2.3.2. Not restricted

2.3. Anatomical changes of a limb

2.3.1. Is the operated limb length the same as the other one?

2.3.1.1. Yes

2.3.1.2. No

2.3.2. Do you have limb deformations?

2.3.2.1. No deformations

2.3.2.2. Deformations exist

After the survey is completed, an interviewer expresses gratitude for participation in the study.

* An interviewer assesses the regularity of visits for each case, i.e., the time that has elapsed since surgery and up to the interview date, according to the national standards of outpatient care for THR/TKR patients.

\section{References}

1. Woolf, A.D.; Pfleger, B. Burden of major musculoskeletal conditions. Bull. World Health Organ. 2003, 81, 646-656.

2. Storheim, K.; Zwart, J.A. Musculoskeletal disorders and the Global Burden of Disease study. Ann. Rheum. Dis. 2014, 73, 949-950. [CrossRef] [PubMed]

3. Litwic, A.; Edwards, M.H.; Dennison, E.M. Cooper Cyrus. Epidemiology and burden of osteoarthritis. Br. Med. Bull. 2013, 105, 185-199. [CrossRef] [PubMed]

4. Conaghan, P.G.; Dickson, J.; Grant, R.L. Guideline Development Group. Care and Management of Osteoarthritis in Adults: Summary of NICE Guidance. BMJ 2008, 336, 502-503. [CrossRef] [PubMed]

5. National Clinical Guideline Centre (UK). Osteoarthritis: Care and Management in Adults; National Institute for Health and Care Excellence (UK): London, UK, 2014.

6. Nelson, A.E.; Allen, K.D.; Golightly, Y.M.; Goode, A.P.; Jordan, J.M. A systematic review of recommendations and guidelines for the management of osteoarthritis: The chronic osteoarthritis management initiative of the U.S. bone and joint initiative. Semin. Arthritis Rheum. 2014, 43, 701-712. [CrossRef] [PubMed]

7. Kremers, M.H.; Larson, D.R.; Crowson, C.S.; Kremers, W.K.; Washington, R.E.; Steiner, C.A.; Jiranek, W.A.; Berry, D.J. Prevalence of total hip and knee replacement in the United States. J. Bone Jt. Surg. Am. 2015, 97, 1386-1397. [CrossRef] [PubMed]

8. Hunt, L.P.; Blom, A.; Wilkinson, J.M. An analysis of 30-day mortality after weekend versus weekday elective joint arthroplasty in England and Wales: A cohort study using the National Joint Registry Dataset. Bone Jt. J. 2017, 99, 1618-1628. [CrossRef] [PubMed]

9. Torre, M.; Romanini, E.; Zanoli, G.; Carrani, E.; Luzi, I.; Leone, L.; Leone, L.; Bellino, S. Monitoring outcome of joint arthroplasty in Italy: Implementation of the National Registry. Joints 2017, 5, 70-78. [CrossRef] [PubMed]

10. van der Wees, P.J.; Wammes, J.J.; Akkermans, R.P.; Koetsenruijter, J.; Westert, G.P.; van Kampen, A.; Hannink, G.; de Waal-Malefijt, M.; Schreurs, B.W. Patient-reported health outcomes after total hip and knee surgery in a Dutch University Hospital Setting: Results of twenty years clinical registry. BMC Musculoskelet. Disord. 2017, 18, 97. [CrossRef]

11. Tikhilov, R.M.; Kornilov, N.N.; Kulyaba, T.A.; Fil', A.S.; Drozdova, P.V.; Petukhov, A.I. Comparative analysis of knee replacement registers (review). Travmatol. Ortop. Ross. 2014, 2, 112-121. [CrossRef]

12. Zagorodniy, N.V. Joint replacement in the Russian Federation. In Proceedings of the Research and Practice Conference Vreden Readings, Saint-Petersburg, Russia, 26-28 September 2013. Available online: http://vredenreadings.org/arc/28/Zagorodny.pdf (accessed on 2 December 2020).

13. Goryannaya, N.A.; Ishekova, N.I.; Popov, V.V.; Bondarenko, E.G. Change of patients' quality of life after hip replacement at the first stage of rehabilitation. Hum. Ecol. 2017, 1, 41-44. [CrossRef]

14. Asilova, S.U.; Ruzibaev, D.R. Medical-and-social examination and rehabilitation of patients and disabled persons after the hip total arthroplasty. Geniy Ortop. 2015, 2, 36-39. [CrossRef]

15. Norkin, I.A.; Baratov, A.V.; Akimova, T.N.; Yushina, B.S.; Vegele, L.S. The traumatological orthopedic service of Region: Problems and goals. Zdr. Ross. Fed. 2014, 58, 12-17.

16. Shubnjakov, I.I.; Tihilov, R.M.; Nikolaev, N.S.; Grigoricheva, L.G.; Ovsjankin, A.V.; Chernyj, A.Z.; Drozdova, P.V.; Denisov, A.O.; Veber, E.V.; Kuz'mina, I.V. Epidemiology of primary hip endoprosthesis on the basis of the data of the register of arthroplasty RSRITO named after R. R. Vreden. Traumatol. Orthop. Russ. 2017, 23, 81-101. [CrossRef]

17. Resources and Activities of Health Care Organizations. Key Indicators of Health Care. Part VI, 2019. Russian. Available online: https:/ / www.rosminzdrav.ru/ministry/61/22/stranitsa-979/statisticheskie-i-informatsionnye-materialy/statisticheskiysbornik-2018-god (accessed on 2 November 2020).

18. Sandakov, J.P.; Kochubej, A.V.; Chernjahovskij, O.B.; Kochubej, V.V. Evaluation of polyclinic rehabilitation after joint endoprosthesis. Probl. Soc. Hyg. Health Care Med. Hist. 2020, 28, 101-105. 
19. Zagorodniy, N.V.; Elkin, D.V.; Banetskiy, M.V.; Sharkeev, V.N.; Grebchenko, N.V.; Kurnikov, D.A. Medium-term results of femoral component of implants "Implant-Elit" by MATI-Medtech use in clinical practice at cementless fixation. Acta Biomed. Sci. 2006, 4, 104-109.

20. Wong, N.M.R.; Cheung, W.L.; Ng, C.K.; Wong, K.K.; Lau, S.W.; Hung, T. A new multi-disciplinary rehabilitation outcome checklist for the rehabilitation of total knee and total hip replacement patients. J. Orthop. Trauma Rehabil. 2013, 17, 40-45. [CrossRef]

21. Woolhead, G.M.; Donovan, J.L.; Dieppe, P.A. Outcomes of total knee replacement: A qualitative study. Rheumatology 2005, 44, 1032-1037. [CrossRef]

22. Stavrev, V.P.; Ilieva, E.M. The holistic approach to rehabilitation of patients after total hip joint replacement. Folia Med. (Plovdiv) 2003, 45, 16-21.

23. Desai, A.S.; Dramis, A.; Board, T.N. Leg length discrepancy after total hip arthroplasty: A review of literature. Curr. Rev. Musculoskelet. Med. 2013, 6, 336-341. [CrossRef]

24. Fedonnikov, A.S. Communication with patients and colleagues in rehabilitation process: Needs, expectations and responsibility of the orthopedic surgeons. Russ. Open Med. J. 2019, 8, e0306. [CrossRef]

25. Fedonnikov, A.; Andriyanova, E.; Grishechkina, N. Online communication-based rehabilitation management for patients with replaced joints: Experience and opportunities. Archiv EuroMedica 2020, 10, 91-94. [CrossRef]

26. Lingard, E.A.; Verven, S.; Katz, J.N. Management and care of patients undergoing total knee arthroplasty: Variations across different health care settings. Arthritis Care Res. 2000, 13, 129-136. [CrossRef]

27. Mahomed, N.N.; Lau, J.T.C.; Lin, M.K.S.; Zdero, R.; Davey, J.R. Significant variation exists in home care services following total joint arthroplasty. J. Rheumatol. 2004, 31, 973-975.

28. Mauer, K.A.; Abrahams, E.B.; Arslanian, C.; Schoenly, L.; Taggart, H.M. National practice patterns for the care of the patient with total joint replacement. Orthop. Nurs. 2002, 21, 37-47. [CrossRef] [PubMed]

29. Canadian Institute for Health Information. Hip and Knee Replacements in Canada-Canadian Joint Replacement Registry (CJRR) 2008-2009 Annual Report; CIHI: Ottawa, ON, Canada, 2009.

30. Donabedian, A. The definition of quality and approaches to its assessment. In Explorations in Quality Assessment and Monitoring; Health Administration Press: Ann Arbor, MI, USA, 1980; Volume 1, pp. 95-99.

31. Breugem, S.J.; Haverkamp, D. Anterior knee pain after a total knee arthroplasty: What can cause this pain? World J. Orthop. 2014, 5, 163-170. [CrossRef]

32. Kastyro, I.V.; Torshin, V.I.; Drozdova, G.A.; Popadyuk, V.I. Acute pain intensity in men and women after septoplasty. Russ. Open Med. J. 2017, 6, e0305. [CrossRef]

33. Edelen, M.O.; Saliba, D. Correspondence of verbal descriptor and numeric rating scales for pain intensity: An item response theory calibration. J. Gerontol. A Biol. Sci. Med. Sci. 2010, 65, 778-785. [CrossRef]

34. Carr, E.C.J.; Mann, E.M. Pain: Creative Approaches to Effective Management; Macmillan Publishers Ltd.: Basingstoke, UK, 2000.

35. Turk, D.C.; Melzack, R. Handbook of Pain Assessment, 2nd ed.; Guilford Press: New York, NY, USA, 2001. 